\title{
Experimental characterization of an Organic Rankine Cycle (ORC) for micro-scale CHP applications
}

\author{
Bernardo Peris ${ }^{*}$ a, Joaquín Navarro-Esbría , Francisco Molés ${ }^{a}$, Jose Pascual Martíb, Adrián Mota- \\ Babiloni ${ }^{\mathrm{a}, \mathrm{c}}$ \\ ${ }^{a}$ ISTENER Research Group. Department of Mechanical Engineering and Construction, Campus de Riu Sec s/n, \\ University Jaume I, E12071, Castellón, Spain. \\ ${ }^{\mathrm{b}}$ Expander-Tech, Campus de Riu Sec s/n, University Jaume I, E12071, Castellón, Spain. \\ ${ }^{\mathrm{c}}$ Institute for Industrial, Radiophysical and Environmental Safety, Camino de Vera s/n, Polytechnic University of \\ Valencia, E-46022 Valencia, Spain.
}

\begin{abstract}
This work conducts an experimental characterization of an Organic Rankine Cycle (ORC) module along the operating conditions expected for micro Combined Heat and Power (CHP) applications. For this, a monitored test bench has been used and adapted to the planned test procedure, which consisted of varying the condensing conditions for a fixed low grade heat source. Thereby, 10 steady state points are achieved and analyzed according to thermal power input, useful heat production, gross and net electrical powers, electrical and thermal cycle efficiencies and expander effectiveness parameters. The results show the importance, for all the cited parameters, that takes to operate with a suited pressure ratio, associated with the expander built-in volume ratio, to each specific application. So, if the useful heat temperature requirements allow to operate with a moderate under-expansion in the expander, the module is optimized.
\end{abstract}

Keywords: Organic Rankine Cycle (ORC); Combined Heat and Power (CHP); test bench; heat recovery; energy efficiency.

\footnotetext{
* Corresponding Author:

Tel: +34 964728137; fax: +34 964728106.

E-mail address: bperis@uji.es
} 


\begin{tabular}{|c|c|}
\hline Nomenc & \\
\hline$c_{p}$ & specific heat capacity $\left(\mathrm{kJ} \cdot \mathrm{kg}^{-1} \cdot \mathrm{K}^{-1}\right)$ \\
\hline $\mathrm{F}_{\mathrm{f}}$ & filling factor $(\%)$ \\
\hline $\mathrm{h}$ & enthalpy $\left(\mathrm{kJ} \cdot \mathrm{kg}^{-1}\right)$ \\
\hline$\dot{\mathrm{m}}$ & mass flow rate $\left(\mathrm{kg} \cdot \mathrm{s}^{-1}\right)$ \\
\hline $\mathrm{N}$ & rotational speed $\left(\mathrm{rev} \cdot \mathrm{s}^{-1}\right)$ \\
\hline $\mathrm{P}$ & pressure (bar) \\
\hline Q & thermal power $(\mathrm{kWt})$ \\
\hline $\mathrm{r}_{\mathrm{p}}$ & pressure ratio \\
\hline $\mathrm{r}_{\mathrm{v}}$ & volume ratio \\
\hline $\mathrm{s}$ & entropy $\left(\mathrm{kJ} \cdot \mathrm{kg}^{-1} \cdot \mathrm{K}^{-1}\right)$ \\
\hline $\mathrm{T}$ & temperature $\left({ }^{\circ} \mathrm{C}\right)$ \\
\hline $\mathrm{U}$ & uncertainty \\
\hline $\mathrm{v}$ & displacement or swept volume $\left(\mathrm{m}^{3} \cdot \mathrm{rev}^{-1}\right)$ \\
\hline$\dot{\mathrm{V}}$ & volumetric flow rate $\left(\mathrm{m}^{3} \cdot \mathrm{s}^{-1}\right)$ \\
\hline W & electrical power $(\mathrm{kWe})$ \\
\hline Greek s. & \\
\hline$\varepsilon$ & effectiveness (\%) \\
\hline$\eta$ & efficiency $(\%)$ \\
\hline$\rho$ & density $\left(\mathrm{kg} \cdot \mathrm{m}^{-3}\right)$ \\
\hline Subscrit & \\
\hline c & condenser \\
\hline e & expander \\
\hline ex & exergetic \\
\hline el & electrical \\
\hline g & gross \\
\hline HRVG & heat recovery vapor generator \\
\hline $\mathrm{i}$ & built-in \\
\hline ise & isentropic \\
\hline $\mathrm{n}$ & net \\
\hline oil & thermal oil \\
\hline $\mathrm{p}$ & pump \\
\hline $\mathrm{t}$ & theoretical \\
\hline th & thermal \\
\hline $\mathrm{W}$ & water-ethylene glycol mixture \\
\hline wf & working fluid \\
\hline
\end{tabular}

\section{Introduction}

When there are useful heat demands, the thermal energy production can be generated along with electricity, requiring little more fuel consumption but providing greater energy, environmental and economic benefits. So, a Combined Heat and Power (CHP) system requires lower primary energy consumption compared to a separate heat and power production, reducing global energy costs and pollutant emissions to the atmosphere. Moreover, the sale or use of the electricity produced can provide economic benefit to the user of the facility. 
Taking these benefits into account, various conversion technologies have been used for CHP applications, such as steam Rankine cycle, Organic Rankine Cycle (ORC), Stirling engine, internal combustion engine, gas turbine and fuel cell [1]. Each one exhibits own advantages according to the heat source used, fossil fuels or renewable energy, temperature application range or thermal and electrical power requirements [2].

Focusing on residential and commercial applications, the ORC has been proposed as a suitable conversion technology, since it can achieve great efficiencies from low grade heat sources and can result cost-effective for micro-scale applications, often referred to an electrical power lower than $15 \mathrm{kWe}$ [3].

In this way, Dong et al. [4] reviewed small and micro-scale biomass-fuelled CHP systems, comparing the ORC to other conversion technologies. The researchers pointed that the ORC encounters technical and economical obstacles, in comparison to medium and large-scale systems, requiring to reduce the specific investment cost and increment the electrical and CHP efficiencies. Experimental results obtained in a preliminary investigation were presented by Farrokhi et al. [5] about a gas-fired ORC-based micro-CHP system for residential buildings. Thereby, using isopentane as working fluid and a vane type of expander, a maximum electrical power output of $0.774 \mathrm{kWe}$ and a net cycle electrical efficiency of $1.66 \%$ were achieved. Similarly, Qiu et al. [6] experimented with a biomass-pellet boiler and an ORC for micro-CHP applications, by heating to $46{ }^{\circ} \mathrm{C}$ the cooling water of the condenser outlet. The main working fluid used was HFE7000 and again a vane type of expander. So, $0.861 \mathrm{kWe}$ were generated with a gross electrical efficiency of $1.41 \%$ and a CHP efficiency of $78.69 \%$. Declaye et al. [7] characterized an oil-free scroll expander using R245fa as working fluid, showing that the cycle could produce up to $50{ }^{\circ} \mathrm{C}$ of useful heat, a maximum shaft power of $2.1 \mathrm{~kW}$ and mechanical efficiency of $8.5 \%$.

As can be seen, the main expansion technology investigated for ORCs, intended for micro-scale CHP applications, is the volumetric or positive displacement machine. The reason is that volumetric expanders result more appropriate in small-scale units than turbo-machines, as they are characterized by lower flow rates, higher pressure ratios, much lower rotational speeds, besides to exhibit good effectiveness and tolerate liquid phase during expansion [8].

Focused on ORCs that use volumetric expanders, various investigations have been carried out in the literature. So, Zhou et al. [9] tested an ORC using the working fluid R123 and a scroll expander, obtaining a maximum expander power output of $0.645 \mathrm{~kW}$ and a cycle efficiency of 8.5\%. Wang et al. [10] tested a low temperature solar ORC using R245fa as working fluid and a rolling-piston as expander. The results showed an average shaft power output of $1.64 \mathrm{~kW}$ and an overall power generation efficiency that ranged between 3.2-4.2\%, depending on the solar collector used. Manolakos et al. [11] used the working fluid R134a and a scroll expander, obtained from a compressor in reverse operation, to demonstrate the technical feasibility of a low-temperature solar ORC for reverse osmosis desalination. So, the results showed net mechanical efficiencies ranging between $0.73 \%$ and $1.17 \%$. Peterson et al. [12] used an ORC with the regenerative cycle configuration, the working fluid R123 and a scroll expander, achieving a gross cycle mechanical efficiency of $7.2 \%$ and an expander mechanical isentropic effectiveness that ranged between 45-50\%. Bracco et al. [13] reported that in the literature the usual expander effectiveness ranges between $60-65 \%$ with peaks of $68-70 \%$, which is in compliance with their results. The researchers tested a small-size ORC prototype using the 
working fluid R245fa and a scroll expander, adapted from a commercial HVAC, achieving a net cycle electrical efficiency around $8 \%$. Kane et al. [14] proposed to use two superposed ORCs, each one with an optimized working fluid and expander to overcome the limited pressure range and built-in volume ratio (Vi) of a scroll expander modified from a standard compressor. The working fluids selected were R123 for the topping ORC and R134a for the bottoming ORC. Thereby, the results showed that the superposed cycle achieved a net electrical efficiency upper $12 \%$ during tests.

Taking into consideration the energy efficiency measure that means a micro-scale CHP system based on ORC, its increasing development in residential and building applications and the contribution of volumetric expanders to achieve a cost-effective ORC, this paper experimentally conducts the performance characterization of an ORC that can satisfy the specifications.

For this purpose, the rest of the paper is organized as follows. Section 2 describes the test bench used. Section 3 exposes the methodology employed, pointing the measuring devices used, equations for the thermodynamic analysis and test procedure. Section 4 presents and discusses the results of the system characterization. And finally, Section 5 summarizes the main conclusions of the work.

\section{Test bench description}

In order to conduct the system performance characterization, a monitored test bench has been used and adapted to the planned operating conditions. So, the main parts of this facility are addressed.

\subsection{Heat source}

A low grade heat source has been simulated using a natural gas boiler and a thermal oil heat transfer loop, as it can be appreciated in Fig.1.a. The facility allows to supply the thermal power demanded by the ORC, besides to control the test conditions. For this, it is composed of two loops. The first one is the loop of the boiler, which is automatically adjusted to the thermal power demand. The second one allows to vary the volumetric flow rate that enters in the ORC, through a pump frequency inverter, and to control the thermal oil inlet temperature in the ORC, using a three way valve and a PID controller.

The basic scheme of the facility is illustrated in Fig.1.b, whose main components are: 1-ORC, 2natural gas boiler, 3-centrifugal pumps, 4-three way valve, 5-expansion tank, 6-main safety valve.

Fig.1. Heat source test bench: (a) general view of the facility and ORC module, (b) basic scheme.

\subsection{Heat sink}

With the aim to characterize the system performance along a wide range of useful heat temperatures for CHP applications, a heat sink facility, shown in Fig.2.a, has been adapted to operate in the planned conditions. It is based on a dry cooler and a heat transfer loop with a mixture of treated water and $20 \%$ of ethylene glycol. Thereby, the heat dissipation conditions and, consequently, the ORC condensation conditions can be controlled. For this, it uses a PID 
controller that allows to adjust the dry cooler fans velocity according to the ORC hot water outlet temperature.

The basic scheme of that facility is illustrated in Fig.2.b, whose main components are: 1-ORC, 7-dry cooler, 8-centrifugal pump, 9-tank, 10-membrane expansion vessel.

Fig.2. Heat sink test bench: (a) general view of the facility, (b) basic scheme.

\subsection{ORC module}

The ORC used in this work is a commercial module from Rank ${ }^{\circledR}$ [15]. This ORC uses a regenerative cycle configuration that allows not only recovering the thermal energy from the heat source, but also the waste heat from the expander outlet to preheat the liquid, improving the cycle electrical efficiency. Regarding to design issues, the module can generate up to $7.5 \mathrm{kWe}$ determined by the electric generator rated power. The rated thermal power is determined by the heat exchangers, which were designed to recover about $60 \mathrm{kWt}$ from the heat source and provide about $55 \mathrm{kWt}$ of useful heat.

These and other features of the ORC module are listed in Table 1.

Table 1. Rank® ORC module features.

\section{Methodology}

In this section the main measuring devices used for the system motoring, equations for the experimental data analysis and test procedure conducted are addressed.

\subsection{System monitoring}

Focusing on the ORC monitoring, the main parameters measured are represented in Fig.3. In the first place, the thermal power input is monitored in the hot side through inlet and outlet thermal oil temperatures, using surface thermocouples, and the thermal oil volumetric flow rate, that is measured using a vortex flow meter. From the thermal power input, the working fluid mass flow rate can be obtained through temperature and pressure conditions at the Heat Recovery Vapor Generator (HRVG) ports. So, two surface thermocouples and a single pressure transmitter are employed, neglecting the HRVG pressure drop. The pressure and temperature devices from the HRVG outlet are placed as near as possible to the expander inlet port, as well as two more measuring devices at the expander outlet port for monitoring its performance. Furthermore, its electrical power output is measured using a wattmeter at the electric generator, while the pump electrical consumption is measured in the electric motor through another wattmeter. Finally, the useful heat produced in the ORC is obtained from the working fluid side at the condenser ports, although two temperature devices are also placed in the hot water side. For this, it is used two surface thermocouples for temperature monitoring and the same pressure transmitter of the expander outlet, assuming a pressure drop of 0.5 bar for calculating the condensing pressure.

Fig.3. Regenerative ORC scheme and main parameters monitored.

With the purpose to exemplify the thermodynamic states of the cycle during typical operating conditions, Table 2 collects the working fluid properties for the ORC producing hot water at 70 ${ }^{\circ} \mathrm{C}$. These working fluid properties have been evaluated using the software REFPROP [16]. 
Table 2 . Thermodynamic states producing hot water at $70{ }^{\circ} \mathrm{C}$.

The measuring devices uncertainties, extracted from manufacturers' data sheets, and the calculated parameters uncertainties $U_{y}$, obtained as a function of the uncertainty on each measured variable $U_{x_{i}}$ by Eq. (1) [17], are collected in Table 3.

$U_{y}=\sqrt{\sum_{i=1}^{N}\left(\frac{\partial y}{\partial x_{i}}\right)^{2} \cdot U_{x_{i}}^{2}}$

Table 3. Uncertainties of measured and calculated parameters.

\subsection{Thermodynamic analysis equations}

For the analysis of the experimental data obtained during tests various equations have been used. Firstly, the thermal power input is calculated through Eq. (2) and the thermal oil properties at the operating conditions. From this, the working fluid mass flow rate can be obtained through Eq. (3). On the other hand, the useful heat produced is calculated as the thermal power output by Eq. (4), being the relationship between both thermal powers defined as the thermal efficiency by Eq. (5).

$$
\begin{aligned}
& Q_{\text {in }}=\rho_{\text {oil out }} \cdot \dot{V}_{\text {oil }, \text { out }} \cdot c_{\text {poil }} \cdot\left(T_{\text {oil }, \text { in }}-T_{\text {oil }, \text { out }}\right) \\
& \dot{m}_{w f}=\frac{Q_{\text {in }}}{h_{e, \text { in }}-h_{H R V G, \text { in }}} \\
& Q_{\text {out }}=\dot{m}_{w f} \cdot\left(h_{c, \text { in }}-h_{c, \text { out }}\right) \\
& \eta_{\text {th }}=\frac{Q_{\text {out }}}{Q_{\text {in }}}
\end{aligned}
$$

The gross electrical power from the electric generator is directly measured, as well as the electrical pump consumption and, therefore, it can be calculated the net power output generated using Eq. (6). The electrical efficiency of the cycle is obtained using the gross electrical efficiency by Eq. (7) and net electrical efficiency by Eq. (8). Moreover, the exergetic or second law efficiency is used, defined in Eq. (9) as the ratio between the net electrical power and the maximum ideally reachable, with temperature in Kelvin.

$$
\begin{aligned}
& W_{n}=W_{g}-W_{p} \\
& \eta_{g}=\frac{W_{g}}{Q_{i n}} \\
& \eta_{n}=\frac{W_{n}}{Q_{i n}}
\end{aligned}
$$




$$
\eta_{e x}=\frac{W_{n}}{Q_{i n} \cdot\left(1-\frac{T_{w, i n}}{T_{\text {oil }, \text { in }}}\right)}
$$

Regarding to the expander, various performance ratios are addressed. So, the relationship between the electrical power measured in the electric generator and the maximum that could be ideally obtained is defined as the electrical isentropic effectiveness, often also named expander overall efficiency, by Eq. (10). Focusing on the energy losses in the expander, the isentropic effectiveness can be defined as Eq. (11), while the volumetric performance is represented as the ratio between the calculated working fluid flow rate and the theoretically displaced by the expander, named filling factor [18], by Eq. (12). Furthermore, the actual performance of the expander can be compared with its theoretical isentropic effectiveness, defined as Eq. (13), which is based on a model of the expander internal performance [17].

$$
\begin{aligned}
& \varepsilon_{e l, \text { ise }}=\frac{W_{g}}{\dot{m}_{w f} \cdot\left(h_{e, \text { in }}-h_{e, \text { out }, \text { ise }}\right)} \\
& \varepsilon_{\text {ise }}=\frac{h_{e, \text { in }}-h_{e, \text { out }}}{h_{e, \text { in }}-h_{e, \text { out }, \text { ise }}} \\
& F_{f}=\frac{\dot{m}_{w f}}{\rho_{e, \text { in }} \cdot \mathrm{v}_{e, \text { in }} \cdot N} \\
& \varepsilon_{t, i s e}=\frac{\left(h_{e, \text { in }}-h_{e, i, \text { ise }}\right)+\frac{1}{\rho_{e, i, \text { ise }}} \cdot 100 \cdot\left(P_{e, i, \text { ise }}-P_{e, \text { out }}\right)}{h_{e, \text { in }}-h_{e, \text { out }, \text { ise }}}
\end{aligned}
$$

Other parameters calculated and used for the analysis are the pressure ratio in the expander, defined by Eq. (14), and the volume ratio by Eq. (15).

$$
\begin{array}{r}
r_{p}=\frac{P_{e, \text { in }}}{P_{e, \text { out }}} \\
r_{v}=\frac{\rho_{e, \text { in }}}{\rho_{e, \text { out }}}
\end{array}
$$

\subsection{Test procedure}

The ORC module was tested in the operating range expected in its usual performance. So, a fixed thermal oil temperature was imposed, as well as the thermal oil and hot water volumetric flow rates, while the inlet dissipation temperature was varied from about $30^{\circ} \mathrm{C}$ to more than 70 ${ }^{\circ} \mathrm{C}$.

As a result, the 10 steady state points shown in Fig. 4 were achieved during tests. These steady state points were obtained in a fluctuation range lower than $1 \%$ on each parameter for at least 10 
minutes. Moreover, the operating range registered for each parameter during tests is listed in Table 4.

Fig.4. Operating points obtained during steady states in tests.

Table 4. Operating range of each parameter obtained during tests.

\section{Results and discussions}

From the experimental data obtained during tests an analysis has been conducted, whose results are exposed and discussed in this section.

In a first step, the thermal power characterization is addressed. Fig.5.a shows that, for an ORC done with a fixed thermal oil inlet temperature and volumetric flow rate, the thermal power captured by the ORC increases with the pressure ratio. This is because lower condensation temperatures allow lower thermal oil outlet temperatures and, hence, higher thermal power captures. If the thermal power input is compared to the thermal power output, as Fig.5.b shows, it can be seen a direct relationship among them. However, despite the thermal power output also increases with the pressure ratio, its useful heat temperature is reduced, as can be appreciated in Fig.5.c. This is due to the direct influence of the hot water temperature on the condensing pressure of the cycle, as Fig. 5.d shows.

Fig.5. Thermal power characterization: (a) pressure ratio influence, (b) thermal power output, (c) hot water inlet temperature, (d) hot water outlet temperature.

Now, the electrical power characterization is addressed. Fig.6.a shows that, as well as the thermal power output, the electrical power increases with the thermal power captured from the heat source. However, if gross and net power outputs are represented in function of pressure ratio, as Fig.6.b and Fig.6.c show, it is noted that the increase trend seems attenuated for higher pressure ratios. The reason is due to the curve of the cycle efficiency, which in turn depends on the expander effectiveness as it can be seen below. Thereby, a maximum gross electrical power of $6.90 \mathrm{kWe}$ and net electrical power of $5.60 \mathrm{kWe}$ are achieved.

Taking into account the importance of the electricity production and useful heat temperature in a CHP application, both parameters have been related in Fig.6.d. It must be mentioned that the ORC module is automatically adjusted to energy demands, providing higher electrical powers for lower useful heat requirements and vice versa.

Fig.6. Electrical power characterization: (a) thermal power input influence, (b) gross electricity with pressure ratio, (c) net electricity with pressure ratio, (d) CHP requirements.

Regarding to the cycle efficiency, Fig.7.a and Fig.7.b show gross and net electrical efficiencies, respectively. It highlights that, in both cases, the efficiency quickly grows with the pressure ratio up to be attenuated, as occurred with the electrical power, and even to reduce it for the highest pressure ratio, as similarly reported Bracco et al. [13]. Obviously, the thermal efficiency draws a sensitively opposite curve, as can be appreciated in Fig.7.c, being higher for lower electrical efficiencies and vice versa. On the other hand, Fig, 7.d. shows the second law or exergetic efficiency. It can be noted that the ratio between the net power output and the maximum theoretically reachable increases up to about a pressure ratio of 6 . Higher pressure ratios reveal technical limitations on the cycle, which are mainly due to the reduction of the 
expander effectiveness. Thereby, a gross electrical efficiency of $10.64 \%$ and a net electrical efficiency of $8.80 \%$ are achieved.

Fig.7. Cycle efficiencies characterization: (a) gross electrical efficiency, (b) net electrical efficiency, (c) thermal efficiency, (d) exergetic efficiency.

Focusing on the expander performance characterization, Fig.8.a shows that the electrical isentropic effectiveness of the expander increases with the pressure ratio when operates in overexpansion, up to about $65 \%$. So, the maximum of this curve is obtained for a volume ratio determined by the expander Vi, located between 5-6 as it is shown in Fig.8.b. However, if the pressure ratio continues increasing, operating in under-expansion, the expander effectiveness is reduced again. Besides under and over-expansion, other energy losses that contribute to draw this curve are heat losses during expansion, frictions, supply pressure drops, internal leakages [8] or the alternator electrical efficiency operating at partial loads [19]. In this way, Fig.8.c shows that the isentropic effectiveness is reduced with the pressure ratio, mainly due to higher heat losses as it was pointed by Clemente et al. [20] or internal leakages. Focusing on the filling factor, as Fig.8.d represents, it seems quite constant in the operating range tested, below $125 \%$ as Zanelli et al. [18], however it can vary when the expander operates at different rotational speeds as reported Declaye et al. [7]. The effect of these energy losses can be appreciated in Fig. 8.e, that represents the measured electrical isentropic effectiveness of the expander and the theoretical internal effectiveness, whose comparison is illustrated in Fig. 8.f.

Fig.8. Expander effectiveness characterization: (a) electrical isentropic effectiveness in function of pressure ratio, (b) in function of volume ratio, (c) isentropic effectiveness, (d) filling factor, (e) energy losses, (f) effectiveness comparison.

\section{Conclusions}

This work has characterized an ORC module in the expected operating conditions for smallscale CHP applications. For this, it has been used a monitored test bench adapted to the planned test procedure. Thus, a fixed low grade heat source, about $165^{\circ} \mathrm{C}$, has been simulated through a natural gas boiler and a heat transfer loop with thermal oil, while the condensing conditions have been varied, from about $30{ }^{\circ} \mathrm{C}$ to more than $70{ }^{\circ} \mathrm{C}$ of hot water inlet temperature, using a controlled dry cooler. So, 10 steady state points have been achieved and analyzed.

Thereby, the results show that the thermal power captured is increased for higher pressure ratios. This also implies higher electrical productions and thermal power outputs. However, in order to provide a suited useful heat temperature for a CHP application the ORC should work with an optimized pressure ratio, since when the ORC operates with low useful heat temperature requirements a higher electrical power can be provided and vice versa.

Regarding to experimental data summary, the maximum electrical powers achieved are a gross power of $6.90 \mathrm{kWe}$ and a net power of $5.60 \mathrm{kWe}$. The maximum cycle efficiencies reached are a gross electrical efficiency of $10.64 \%$ and a net electrical efficiency of $8.80 \%$. With respect to the useful heat, a maximum thermal power output of $58.14 \mathrm{kWt}$, thermal efficiency of $89.28 \%$ and hot water outlet temperature of $80.84{ }^{\circ} \mathrm{C}$ are obtained.

Moreover, focused on the expander characterization it has been observed that it has a direct influence on the cycle efficiency and, hence, on the electrical power. So, the maximum 
electrical efficiency appears when the optimum pressure ratio of the expander is overcome, imposed by the $\mathrm{Vi}$, operating with a moderate under expansion. Much higher pressure ratios are not desirable, since the declining trend of the expander electrical isentropic effectiveness attenuates the cycle efficiency, even up to reduce it for excessive pressure ratios.

\section{Acknowledgements}

The authors want to acknowledge all the invaluable cooperation of Rank®, the ORC manufacturer, for its support in this project. Also to thank greatly the Jaume I University for its financial support under the PhD grant PREDOC/2013/28 of "Convocatòria d'ajudes predoctorals per a la formació de personal investigador del Pla de promoció de la investigació de la Universitat Jaume I de Castelló (Spain)".

\section{References}

[1] Prando D, Patuzzi F, Pernigotto G, Gasparella A, Baratieri M. Biomass gasification systems for residential application: An integrated simulation approach. Applied Thermal Engineering 2014; 71: 152-160.

[2] Villarini M, Bocci E, Moneti M, Di Carlo A, Micangeli A. State of art of small scale solar powered ORC systems: a review of the different typologies and technology perspectives. Energy Procedia 2014; 45: 257 - 267.

[3] Dentice d'Accadia M, Ssso M, Sibilio S, Vanoli L. Micro-combined heat and power in residential and light commercial applications. Applied Thermal Engineering 2003; 23: 12471259.

[4] Dong L, Liu H, Riffat S. Development of small-scale and micro-scale biomass-fuelled CHP systems -A literature review. Applied Thermal Engineering 2009; 29: 2119-2126.

[5] Farrokhi M, Noie SH, Akbarzadeh AA. Preliminary experimental investigation of a natural gas-fired ORC-based micro-CHP system for residential buildings. Applied Thermal Engineering 2014; 69: 221-229.

[6] Qiu G, Shao Y, Li J, Liu H, Riffat SB. Experimental investigation of a biomass-fired ORCbased micro-CHP for domestic applications. Fuel 2012; 96: 374-382.

[7] Declaye S, Quoilin S, Guillaume L, Lemort V. Experimental study on an open-drive scroll expander integrated into an ORC (Organic Rankine Cycle) system with R245fa as working fluid. Energy 2013; 55: 173-183.

[8] Quoilin S, Van Den Broek M, Declaye S, Dewallef P, Lemort V. Techno-economic survey of Organic Rankine Cycle (ORC) systems. Renewable and Sustainable Energy Reviews 2013; 22: $168-186$.

[9] Zhou N, Wang X, Chen Z, Wang Z. Experimental study on Organic Rankine Cycle for waste heat recovery from low-temperature flue gas. Energy 2013; 55: 216-225.

[10] Wang XD, Zhao L, Wang JL, Zhang WZ, Zhao XZ, Wu W. Performance evaluation of a low-temperature solar Rankine cycle system utilizing R245fa. Solar Energy 2010; 84: 353-364. 
[11] Manolakos D, Kosmadakis G, Kyritsi S, Papadakis G. On site experimental evaluation of a low-temperature solar organic Rankine cycle system for RO desalination. Solar Energy 2009; 83: 646-656.

[12] Peterson RB, Wang H, Herron T. Performance of small-scale regenerative Rankine power cycle employing a scroll expander. Proceedings of the Institution of Mechanical Engineers, Part A: Journal of Power and Energy 2008; 222: 271-282.

[13] Bracco R, Clemente S, Micheli D, Reini M. Experimental tests and modelization of a domestic-scale ORC (Organic Rankine Cycle). Energy 2013; 58: 107-116.

[14] Kane M, Larrain D, Favrat D, Allani Y. Small hybrid solar power system. Energy 2003; 28: $1427-1443$.

[15] Rank®. Castellon, Spain. Available from: <www.rankweb.es> [accessed 29.07.14].

[16] Lemmon E, Huber M, McLinden M. NIST REFPROP standard reference database 23. Version 8.0. User's guide. NIST; 2007.

[17] Lemort V, Quoilin S, Cuevas C, Lebrun J. Testing and modeling a scroll expander integrated into an Organic Rankine Cycle. Applied Thermal Engineering 2009; 29: 3094-3102.

[18] Zanelli R, Favrat D, Experimental Investigation of a Hermetic Scroll Expander-Generator, in: Proceedings of the International Compressor Engineering Conference at Purdue, 1994, 459464.

[19] Erhart T, Eicker U, Infield D. Part-load characteristics of Organic-Rankine-Cycles. 2nd European Conference on Polygeneration at Tarragona, Spain; 2011.

[20] Clemente S, Micheli D, Reini M, Taccani R. Energy efficiency analysis of Organic Rankine Cycles with scroll expanders for cogenerative applications. Applied Energy 2012; 97: 792-801. 


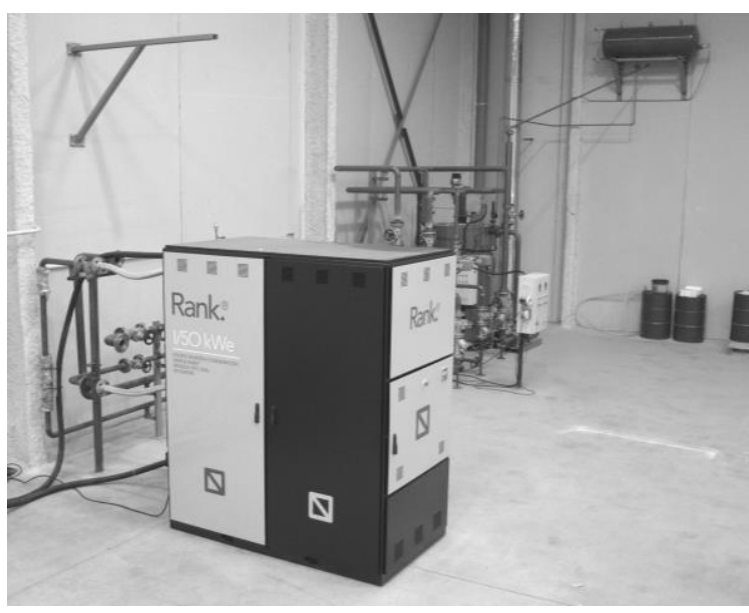

(a)

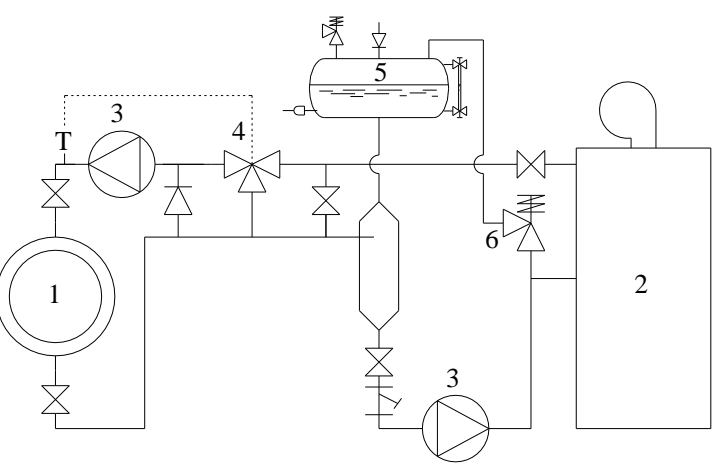

(b)

Fig.1. Heat source test bench: (a) general view of the facility and ORC module, (b) basic scheme. 


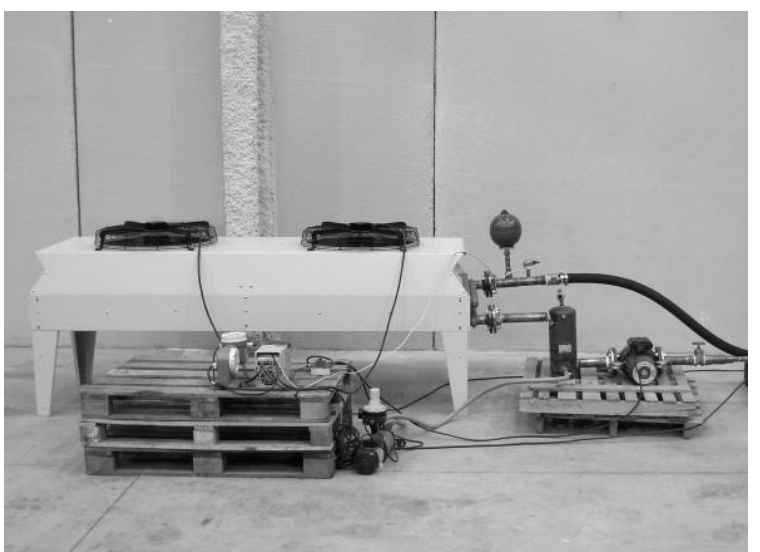

(a)

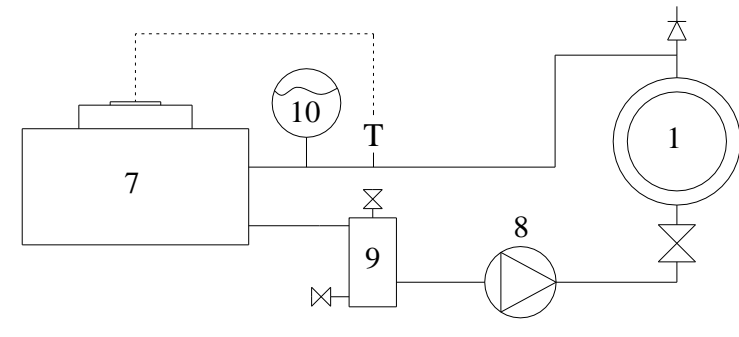

(b)

Fig.2. Heat sink test bench: (a) general view of the facility, (b) basic scheme. 


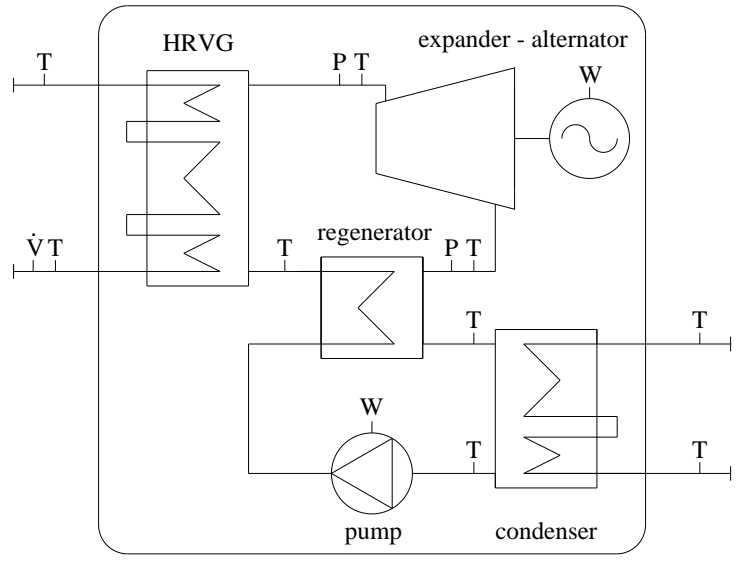

Fig.3. Regenerative ORC scheme and main parameters monitored. 


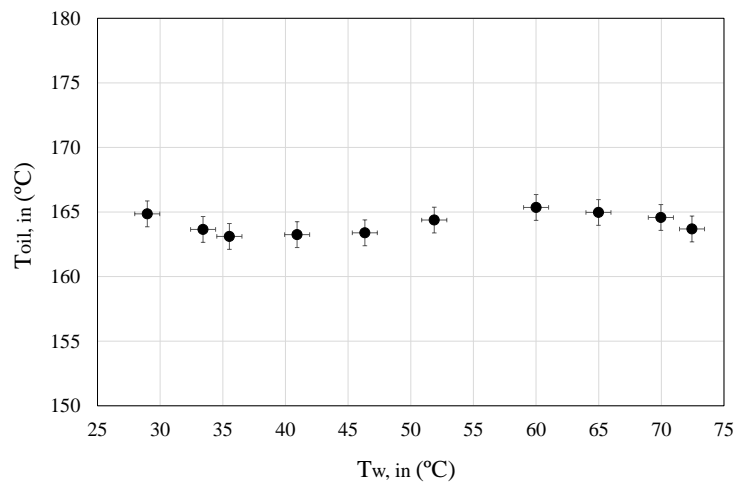

Fig.4. Operating points obtained during steady states in tests. 


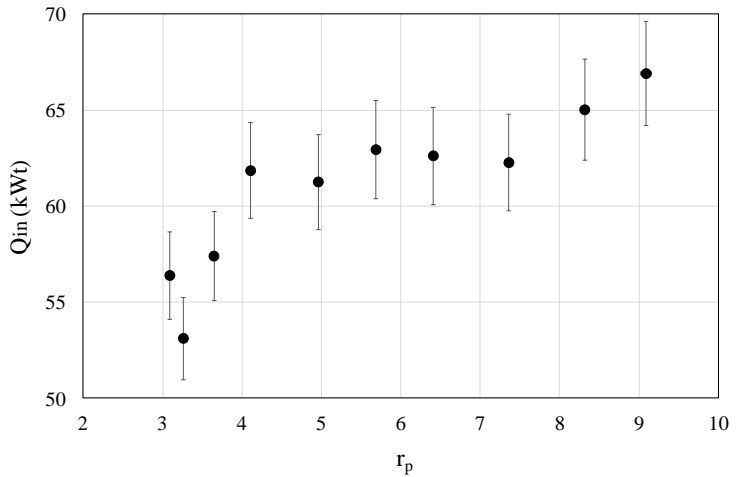

(a)

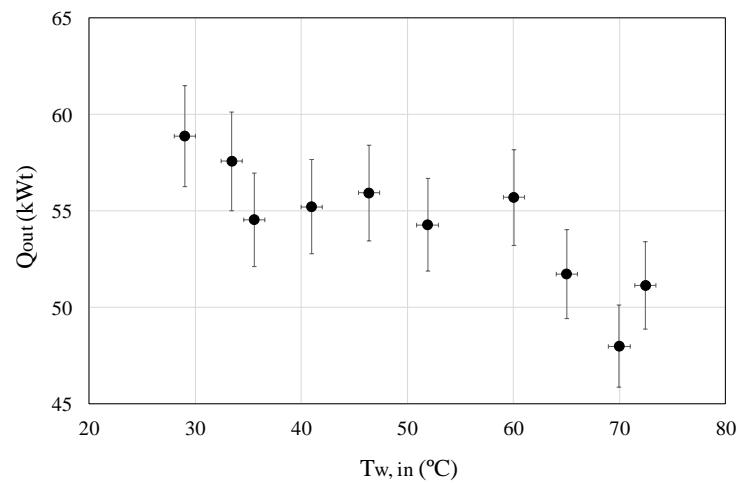

(C)

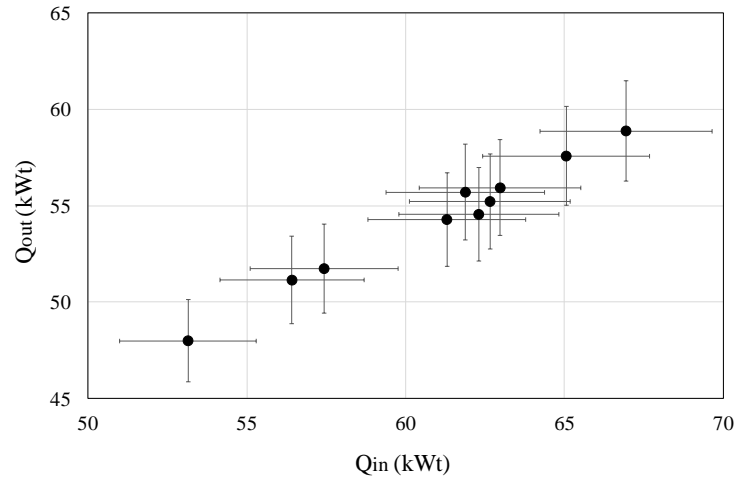

(b)

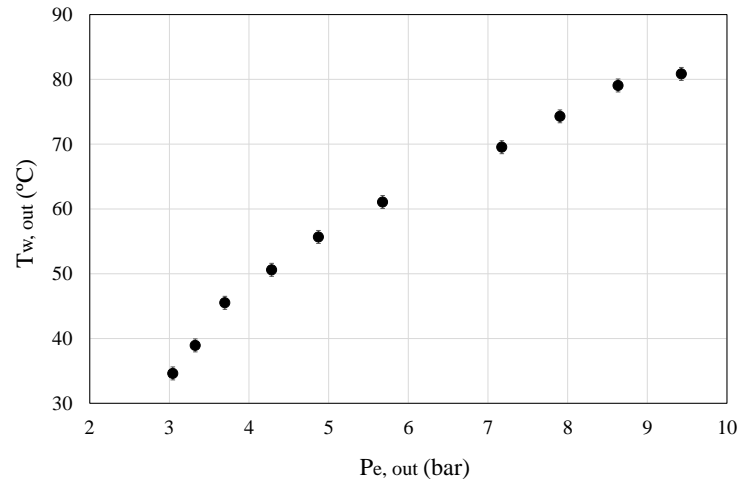

(d)

Fig.5. Thermal power characterization: (a) pressure ratio influence, (b) thermal power output, (c) hot water inlet temperature, (d) hot water outlet temperature. 


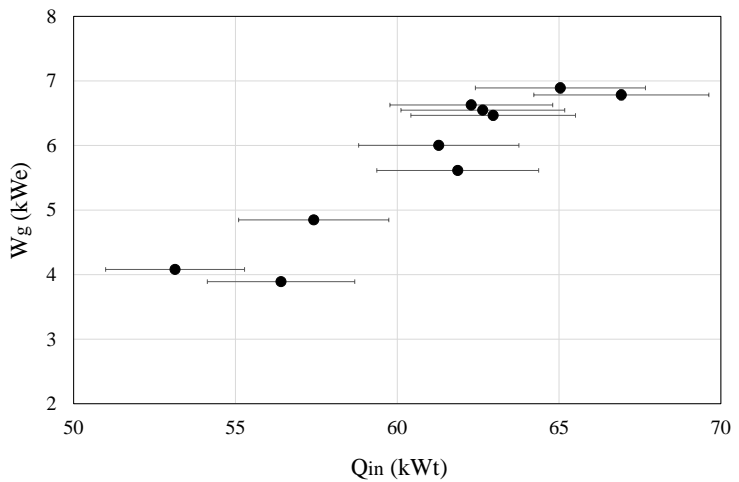

(a)

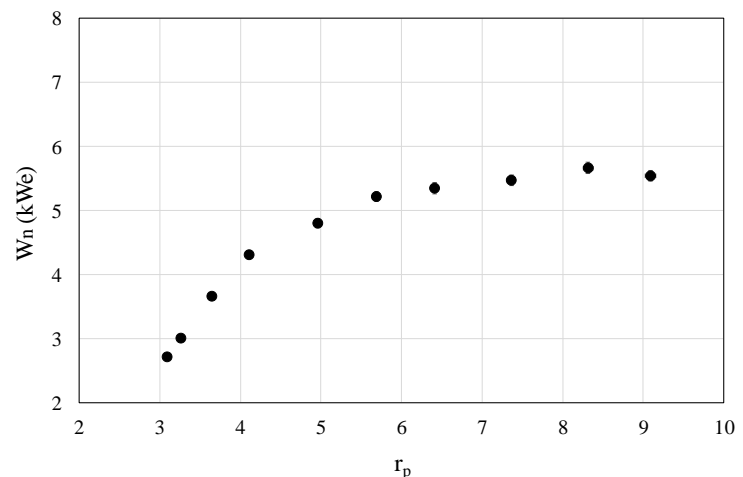

(c)

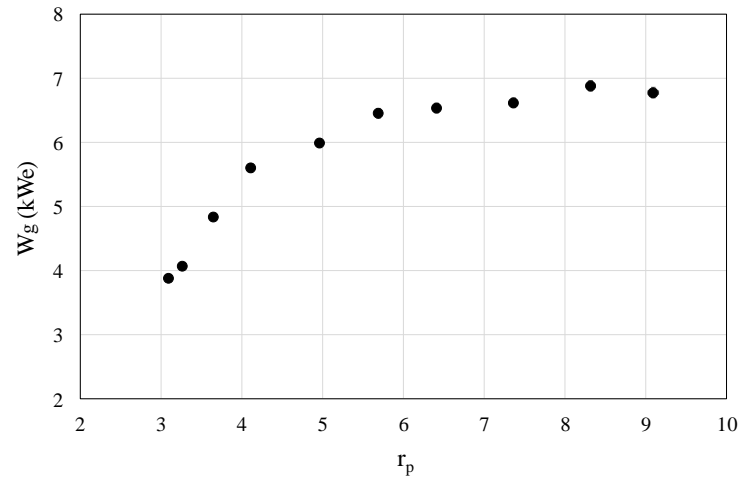

(b)

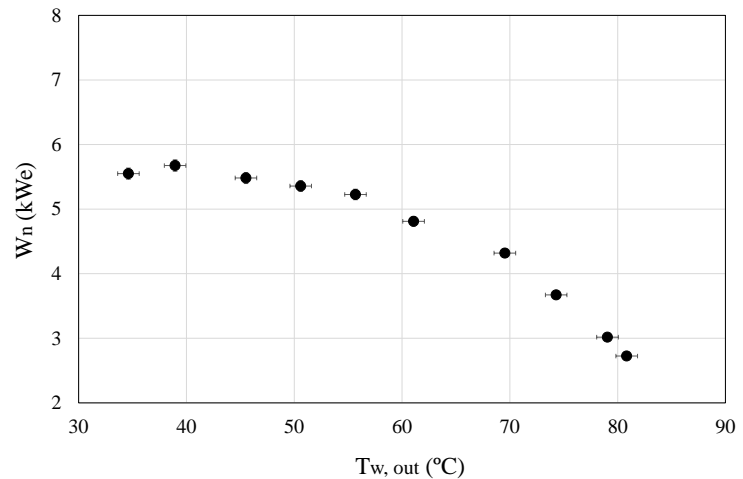

(d)

Fig.6. Electrical power characterization: (a) thermal power input influence, (b) gross electricity with pressure ratio, (c) net electricity with pressure ratio, (d) CHP requirements. 


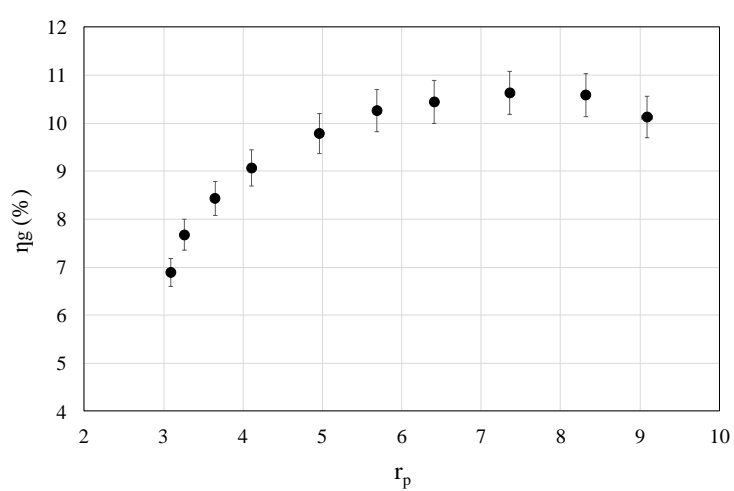

(a)

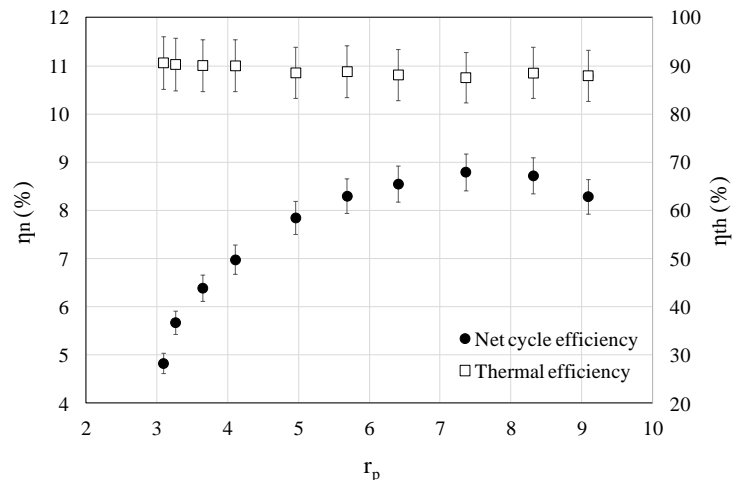

(c)

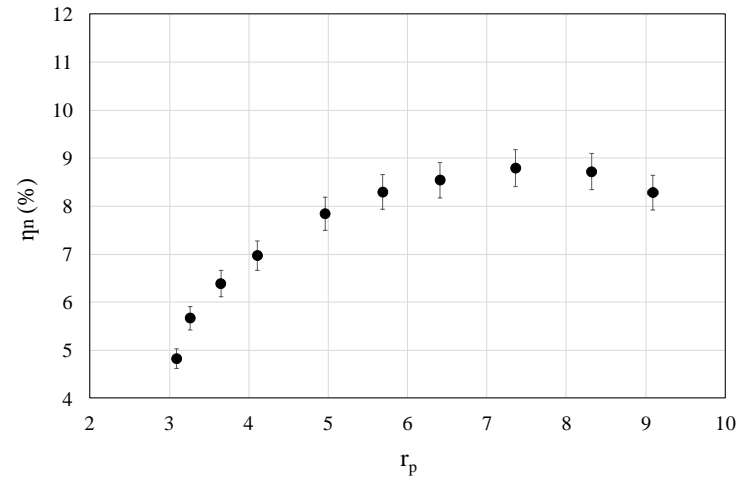

(b)

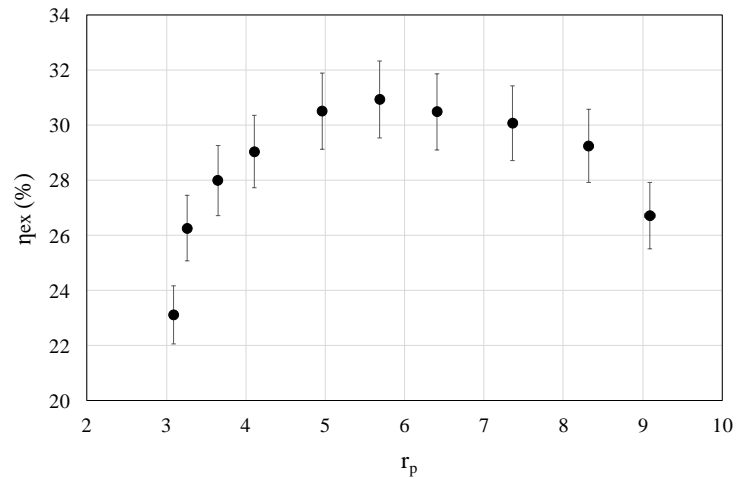

(d)

Fig.7. Cycle efficiencies characterization: (a) gross electrical efficiency, (b) net electrical efficiency, (c) thermal efficiency, (d) exergetic efficiency. 


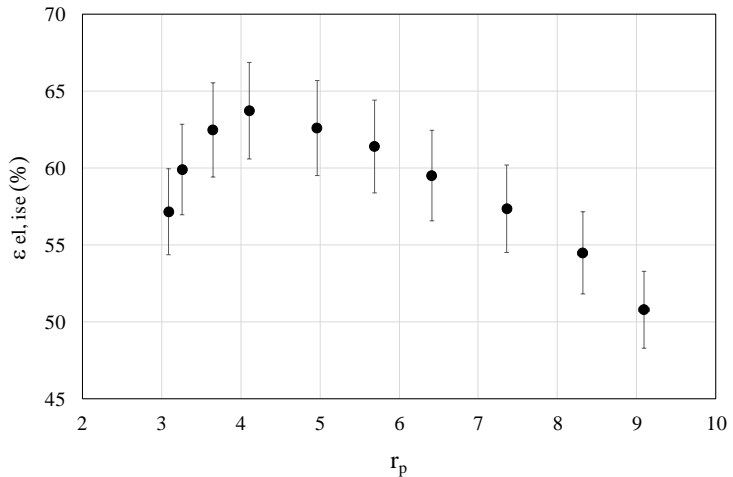

(a)

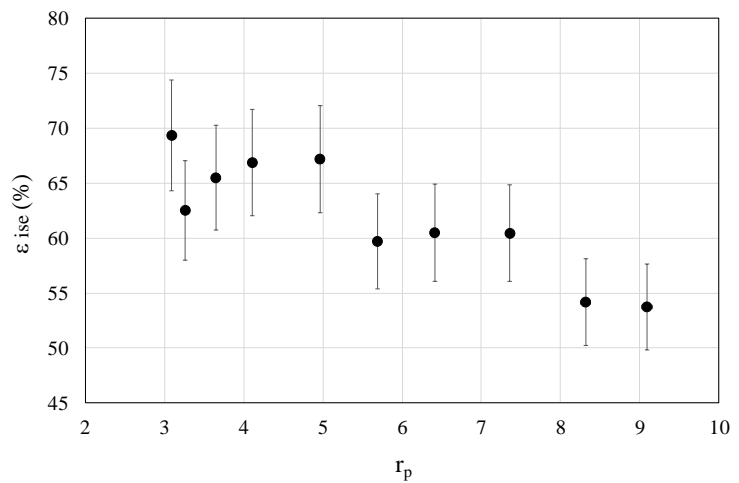

(c)

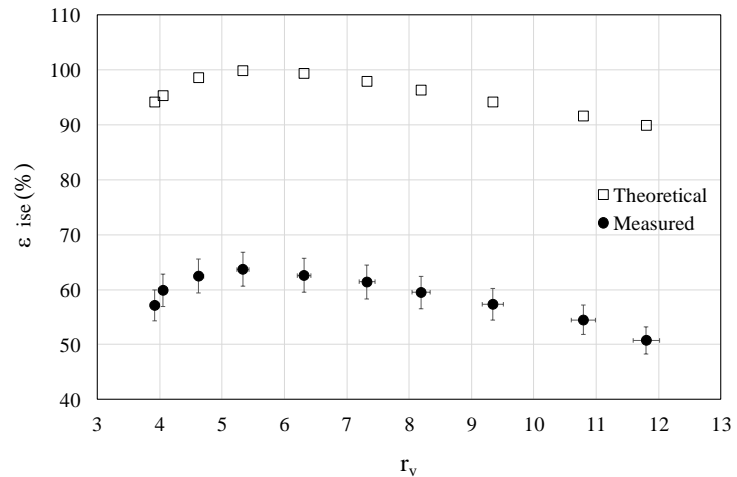

(e)

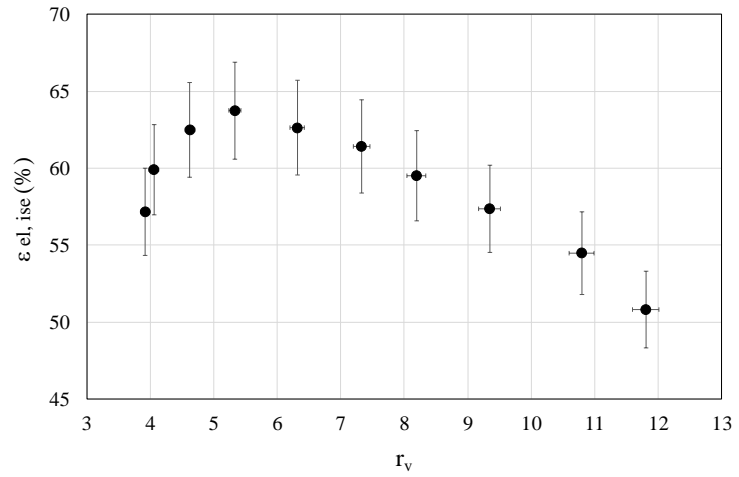

(b)

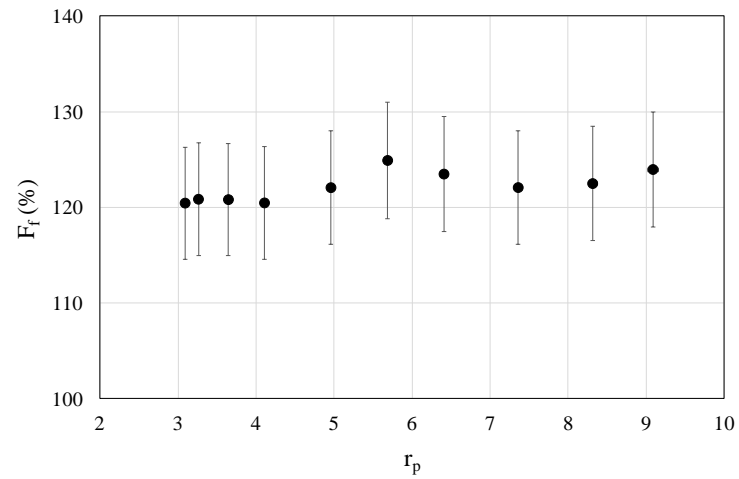

(d)

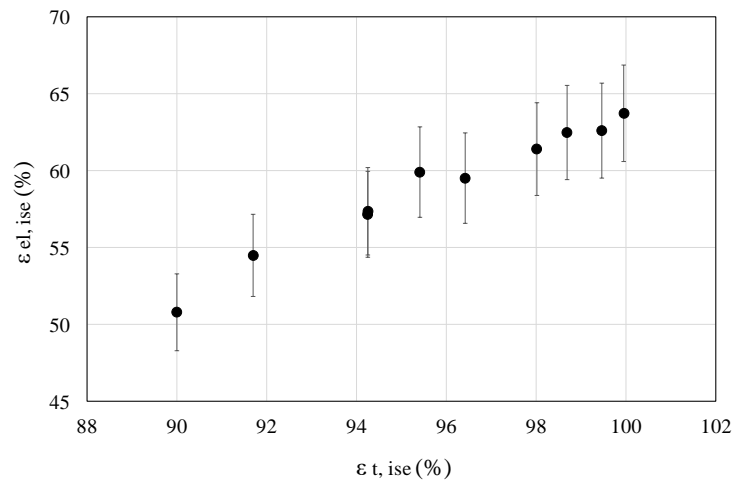

(f)

Fig.8. Expander effectiveness characterization: (a) electrical isentropic effectiveness in function of pressure ratio, (b) in function of volume ratio, (c) isentropic effectiveness, (d) filling factor, (e) energy losses, (f) effectiveness comparison. 


\section{Figure captions}

Fig.1. Heat source test bench: (a) general view of the facility and ORC module, (b) basic scheme.

Fig.2. Heat sink test bench: (a) general view of the facility, (b) basic scheme.

Fig.3. Regenerative ORC scheme and main parameters monitored.

Fig.4. Operating points obtained during steady states in tests.

Fig.5. Thermal power characterization: (a) pressure ratio influence, (b) thermal power output, (c) hot water inlet temperature, (d) hot water outlet temperature.

Fig.6. Electrical power characterization: (a) thermal power input influence, (b) gross electricity with pressure ratio, (c) net electricity with pressure ratio, (d) CHP requirements.

Fig.7. Cycle efficiencies characterization: (a) gross electrical efficiency, (b) net electrical efficiency, (c) thermal efficiency, (d) exergetic efficiency.

Fig.8. Expander effectiveness characterization: (a) electrical isentropic effectiveness in function of pressure ratio, (b) in function of volume ratio, (c) isentropic effectiveness, (d) filling factor, (e) energy losses, (f) effectiveness comparison. 
Table 1. Rank® ORC module features.

\begin{tabular}{lr}
\hline Alternator rated power $(\mathrm{kWe})$ & 7.5 \\
Rated thermal power input $(\mathrm{kWt})$ & 60 \\
Rated thermal power output $(\mathrm{kWt})$ & 55 \\
ORC configuration & regenerative \\
Working fluid & $\mathrm{R} 245 \mathrm{fa}$ \\
Expander technology & volumetric \\
Heat exchangers type & brazed plate \\
Maximum activation temperature $\left({ }^{\circ} \mathrm{C}\right)$ & 170 \\
Maximum hot water outlet temperature $\left({ }^{\circ} \mathrm{C}\right)$ & 90 \\
\hline
\end{tabular}


Table 2 . Thermodynamic states producing hot water at $70{ }^{\circ} \mathrm{C}$.

\begin{tabular}{lccccc}
\hline & $\mathrm{T}\left({ }^{\circ} \mathrm{C}\right)$ & $\mathrm{P}(\mathrm{bar})$ & $\rho\left(\mathrm{kg} \cdot \mathrm{m}^{-3}\right)$ & $\mathrm{h}\left(\mathrm{kJ} \cdot \mathrm{kg}^{-1}\right)$ & $\mathrm{s}\left(\mathrm{kJ} \cdot \mathrm{kg}^{-1} \cdot \mathrm{K}^{-1}\right)$ \\
HRVG in & 89.98 & 29.44 & $1,149.74$ & 323.87 & 1.38 \\
Expander in & 150.91 & 29.44 & 185.47 & 507.64 & 1.84 \\
Expander out & 103.30 & 7.17 & 34.82 & 490.14 & 1.86 \\
Condenser in & 74.67 & 6.67 & 36.80 & 458.78 & 1.78 \\
Condenser out & 69.08 & 6.67 & $1,207.92$ & 293.27 & 1.30 \\
\hline
\end{tabular}


Table 3. Uncertainties of measured and calculated parameters.

\begin{tabular}{lr}
\hline Parameter & $\mathrm{U}$ \\
\hline Temperature $\left({ }^{\circ} \mathrm{C}\right)$ & \pm 1 \\
Pressure (\%) & 0.5 \\
Thermal oil volumetric flow rate (\%) & 0.75 \\
Electrical power (\%) & 1.20 \\
\hline Thermal power input (\%) & 4.04 \\
Working fluid mass flow rate (\%) & 4.22 \\
Thermal power output (\%) & 4.56 \\
Thermal efficiency (\%) & 6.09 \\
Net electrical power (\%) & 1.57 \\
Gross cycle electrical efficiency (\%) & 4.21 \\
Net cycle electrical efficiency (\%) & 4.33 \\
Exergetic efficiency (\%) & 4.54 \\
Electrical isentropic effectiveness $(\%)$ & 4.92 \\
Isentropic effectiveness (\%) & 7.27 \\
Filling factor (\%) & 4.87 \\
Pressure ratio (\%) & 0.71 \\
Volume ratio (\%) & 1.79 \\
\hline
\end{tabular}


Table 4. Operating range of each parameter obtained during tests.

\begin{tabular}{lr}
\hline Parameter & Operating range \\
\hline $\mathrm{T}_{\text {oil, in }}\left({ }^{\circ} \mathrm{C}\right)$ & $163.11-165.36$ \\
$\mathrm{~T}_{\text {oil, out }}\left({ }^{\circ} \mathrm{C}\right)$ & $123.54-132.64$ \\
$\dot{\mathrm{V}}_{\text {oil }}\left(\mathrm{m}^{3} \cdot \mathrm{s}^{-1}\right)$ & $8.45 \mathrm{E}-4-9.49 \mathrm{E}-4$ \\
$\mathrm{~T}_{\mathrm{w}, \text { in }}\left({ }^{\circ} \mathrm{C}\right)$ & $28.97-72.44$ \\
$\mathrm{~T}_{\mathrm{w}, \text { out }}\left({ }^{\circ} \mathrm{C}\right)$ & $34.62-80.84$ \\
$\mathrm{P}_{\mathrm{e}, \text { in }}($ bar $)$ & $27.20-29.44$ \\
$\mathrm{P}_{\mathrm{e}, \text { out }}(\mathrm{bar})$ & $3.04-9.43$ \\
$\mathrm{~T}_{\mathrm{e}, \text { in }}\left({ }^{\circ} \mathrm{C}\right)$ & $148.59-151.22$ \\
$\mathrm{~T}_{\mathrm{e}, \text { out }}\left({ }^{\circ} \mathrm{C}\right)$, & $93.44-112.29$ \\
$\mathrm{~T}_{\mathrm{HRVG}}$ in $\left({ }^{\circ} \mathrm{C}\right)$ & $70.11-99.16$ \\
$\mathrm{~T}_{\mathrm{c}, \text { in }}\left({ }^{\circ} \mathrm{C}\right)$ & $44.45-84.67$ \\
$\mathrm{~T}_{\mathrm{c}, \text { out }}\left({ }^{\circ} \mathrm{C}\right)$ & $37.40-80.96$ \\
$\mathrm{~W}_{\mathrm{g}}(\mathrm{kWe})$ & $3.89-6.90$ \\
$\mathrm{~W}_{\mathrm{p}}(\mathrm{kWe})$ & $1.06-1.30$ \\
\hline
\end{tabular}

